\title{
Rising incidence, no change in survival and decreasing mortality from thyroid cancer in The Netherlands since 1989
}

\author{
Olga Husson ${ }^{1,2}$, Harm R Haak ${ }^{3}$, Liza N van Steenbergen ${ }^{2}$, Willy-Anne Nieuwlaat ${ }^{4}$, \\ Boukje A C van Dijk ${ }^{5}$, Grard A P Nieuwenhuijzen ${ }^{6}$, Henrike Karim-Kos ${ }^{7}$, \\ Johannes L Kuijpens $^{8}$, Lonneke V van de Poll-Franse ${ }^{1,2}$ and Jan Willem W Coebergh ${ }^{2,7}$ \\ 'Department of Medical Psychology and Neuropsychology, Center of Research on Psychology in Somatic Diseases \\ (CoRPS), Tilburg University, Warandelaan 2, PO Box 90153, 5000 LE Tilburg, The Netherlands \\ ${ }^{2}$ Comprehensive Cancer Centre South (CCCS), Eindhoven Cancer Registry, Eindhoven, The Netherlands \\ ${ }^{3}$ Maxima Medisch Centrum Eindhoven, Department of Endocrinology, Eindhoven, The Netherlands \\ ${ }^{4}$ Department of Endocrinology, Elisabeth Hospital Tilburg, Tilburg, The Netherlands \\ ${ }^{5}$ Department of Registry and Research, Comprehensive Cancer Centre the Netherlands (IKNL), Utrecht, \\ The Netherlands \\ ${ }^{6}$ Department of Surgery, Catharina Hospital Eindhoven, Eindhoven, The Netherlands \\ ${ }^{7}$ Department of Public Health, Erasmus MC University Medical Centre Rotterdam, Rotterdam, The Netherlands \\ ${ }^{8}$ VGZ Health Insurance Company, Eindhoven, The Netherlands
}

Correspondence should be addressed to $O$ Husson

Email

o.husson@

tilburguniversity.edu

\begin{abstract}
The incidence of thyroid cancer (TC) is increasing worldwide, partly due to increased detection. We therefore assessed combined trends in incidence, survival and mortality of the various types of TC in The Netherlands between 1989 and 2009. We included all patients $\geq 15$ years with TC, diagnosed in the period 1989-2009 and recorded in The Netherlands Cancer Registry $(n=8021)$. Information on age, gender, date of diagnosis, histological type of tumour and tumour-node-metastasis classification was recorded. Mortality data (up to 1st January 2010) were derived from Statistics Netherlands. Annual percentages of change in incidence, mortality and relative survival were calculated. Since 1989 the incidence of TC increased significantly in The Netherlands (estimated annual percentage change $(E A P C)=+1.7 \%)$. The incidence rates increased for all age groups (except for females $>60$ years), papillary tumours $(\mathrm{EAPC}=+3.5 \%), \mathrm{T} 1$ and $\mathrm{T} 3 \mathrm{TC}(\mathrm{EAPC}=+7.9$ and $+5.8 \%$ respectively). Incidence rates decreased for T4 TC (-2.3\%) and remained stable for follicular, medullary anaplastic and T2 TC. Five-year relative survival rates remained stable for papillary (88\%) and follicular (77\%) TC, all age groups and T1-T3 TC (96, 94 and 80\% respectively) and somewhat lower for T4 (53\%), medullary (65\%) and anaplastic TC (5\%) in the 2004-2009 period compared with earlier periods. Mortality due to TC decreased (EAPC $=-1.9 \%$ ). TC detection and incidence has been rising in The Netherlands, while mortality rates are decreasing and survival rates remained stable or slightly decreasing.
\end{abstract}

\section{Key Words}

- thyroid carcinoma

- incidence

- mortality

- time trends

- survival

- histology http://erc.endocrinology-journals.org DOI: 10.1530/ERC-12-0336
(C) 2013 Society for Endocrinology Printed in Great Britain
Published by Bioscientifica Ltd
Endocrine-Related Cancer (2013) 20, 263-271 


\section{Introduction}

In recent years, the incidence of thyroid cancer (TC) has increased in the USA and most European countries (Davies \& Welch 2006, Ferlay et al. 2010). TC is the most common endocrine malignancy (van der Zwan et al. 2012). The higher incidence rates are often attributed to increased environmental radiation exposure (Cardis et al. 2006), radiation therapy for the treatment of the head and neck areas (Schneider \& Sarne 2005), lower iodine intake (Ceresini et al. 2012) or higher prevalence of obesity (Kitahara et al. 2011). However, the exact aetiology of TC remains unclear. It is also suggested that increasing use of more precise diagnostic imaging might contribute to an increased identification of subclinical disease (Davies \& Welch 2006, Kent et al. 2007). Although a larger portion of small tumours then appear to have been detected, slightly increased incidence rates of larger tumours are also observed (Kent et al. 2007). Contrary to the increasing incidence, mortality from TC remained stable in North America (Davies \& Welch 2006) and decreased (-23 and $-28 \%$, for men and women respectively) in the European Union (Pacini et al. 2010) and prognosis is good (except for the anaplastic type of tumour).

The combined measurements of TC burden (i.e. incidence, mortality and survival) could indicate whether and where progress had been made in cancer diagnosis and treatment and where improvements might be needed.
As none of the previous studies described all three determinants of TC burden in combination, we assessed long-term trends in incidence, mortality and survival of TC in The Netherlands between 1989 and 2009. We hypothesised that in the absence of a clear pattern of aetiological/ environmental exposures the rising incidence might be largely due to increased diagnostic scrutiny, leading to an increased detection of small tumours. If the incidence of small tumours would increase, due to its excellent prognosis, we expect the overall survival rates to increase.

\section{Materials and methods}

\section{Data collection}

Population-based data were used from the nationwide Netherlands Cancer Registry (NCR), which was started in 1989 and combines data from eight Dutch regional cancer registries, currently merged into two. The NCR is based on notification of all new diagnosed malignancies in The Netherlands by the pathological anatomical national automated archive (PALGA), supplemented by notifications from the national registry of hospital discharge, various clinical chemistry laboratories and radiotherapy institutions. Information on patient (sex, date of birth) and tumour characteristics (date of diagnosis, histology,

Table 1 Age, histology and T factor of TC patients in The Netherlands 1989-2009 $(n=8021)$ according to period and sex.

\begin{tabular}{|c|c|c|c|c|c|c|c|c|}
\hline & \multicolumn{4}{|c|}{ Males } & \multicolumn{4}{|c|}{ Females } \\
\hline & $\begin{array}{c}1989-1993 \\
n=437 \\
n(\%)\end{array}$ & $\begin{array}{c}1994-1998 \\
n=504 \\
n(\%)\end{array}$ & $\begin{array}{c}1999-2003 \\
n=542 \\
n(\%)\end{array}$ & $\begin{array}{c}2004-2009^{a} \\
n=858 \\
n(\%)\end{array}$ & $\begin{array}{c}1989-1993 \\
n=1149 \\
n(\%)\end{array}$ & $\begin{array}{c}1994-1998 \\
n=1188 \\
n(\%)\end{array}$ & $\begin{array}{c}1999-2003 \\
n=1335 \\
n(\%)\end{array}$ & $\begin{array}{c}2004-2009^{a} \\
n=2008 \\
n(\%)\end{array}$ \\
\hline \multicolumn{9}{|l|}{ Age (years) } \\
\hline$<45$ & $164(38)$ & $172(34)$ & $178(33)$ & $271(32)$ & $456(40)$ & $470(40)$ & $572(43)$ & 778 (39) \\
\hline $45-59$ & $121(28)$ & $131(26)$ & $155(29)$ & $250(29)$ & $222(19)$ & $279(23)$ & $313(23)$ & $528(26)$ \\
\hline $60-74$ & $100(23)$ & $124(25)$ & $125(23)$ & $227(26)$ & $298(26)$ & $257(22)$ & $244(18)$ & 383 (19) \\
\hline$\geq 75$ & $52(12)$ & 77 (15) & $84(15)$ & $110(13)$ & $173(15)$ & $182(15)$ & $206(15)$ & $319(16)$ \\
\hline \multicolumn{9}{|l|}{ Histology } \\
\hline Papillary carcinoma & $213(49)$ & $261(52)$ & $306(56)$ & $529(62)$ & $604(53)$ & $684(58)$ & $846(63)$ & $1359(68)$ \\
\hline Follicular carcinoma & $108(25)$ & $113(22)$ & $114(21)$ & $173(20)$ & $311(27)$ & $272(23)$ & $280(21)$ & $352(18)$ \\
\hline Medullary carcinoma & $62(14)$ & 73 (14) & $57(11)$ & $90(10)$ & $80(7)$ & $91(8)$ & $69(5)$ & $95(5)$ \\
\hline Anaplastic carcinoma & $18(4)$ & $29(5)$ & $35(6)$ & 32 (4) & $71(6)$ & $73(6)$ & $78(6)$ & $108(5)$ \\
\hline Other & $36(8)$ & $28(6)$ & $30(6)$ & $34(4)$ & $83(7)$ & $68(6)$ & $62(5)$ & $94(5)$ \\
\hline \multicolumn{9}{|l|}{$\mathrm{T}$ factor } \\
\hline 1 & $54(12)$ & $80(16)$ & 89 (16) & $249(29)$ & $164(14)$ & $174(15)$ & 258 (19) & $731(36)$ \\
\hline 2 & $151(35)$ & $147(29)$ & $170(31)$ & $168(20)$ & 457 (40) & $508(43)$ & $541(41)$ & $506(25)$ \\
\hline 3 & 56 (13) & 69 (14) & $87(16)$ & $233(27)$ & $124(11)$ & $140(12)$ & $160(12)$ & $392(20)$ \\
\hline 4 & $96(22)$ & $105(21)$ & $107(20)$ & $120(14)$ & $242(21)$ & 219 (18) & $238(18)$ & 239 (12) \\
\hline$X$ & 80 (18) & $101(20)$ & 89 (16) & 83 (10) & $161(14)$ & $144(12)$ & $137(10)$ & $133(7)$ \\
\hline
\end{tabular}

${ }^{\mathrm{a}}$ Six-year period.

http://erc.endocrinology-journals.org DOI: 10.1530/ERC-12-0336 (c) 2013 Society for Endocrinology Printed in Great Britain 
location, T factor (tumour-node-metastasis (TNM) classification; Hermanek \& Sobin 1987, Sobin \& Fleming 1997, Wittekind et al. 2002) was routinely obtained from the medical records 6-12 months after diagnosis.

Vital status was actively obtained on a regular basis from the municipal registries and from the database of deceased persons of the Central Bureau for Genealogy (date of last follow-up: 1st January 2010). Survival time was calculated as the time from diagnosis to death or to 1st January 2010 or to date of emigration.

Topography and histology were coded according to the International Classification of Diseases for Oncology (ICD-O-3; Fritz et al. 2000). All tumours with an ICD-O-3 topography code thyroid (C73) diagnosed in the period 1989-2009 were included in this study $(n=8021)$. The following histological categories were used: papillary cancer (morphology codes 8050, 8201, 8260, 8340-8344, $8350,8504)$, follicular cancer $(8290,8330-8332,8335)$, medullary cancer $(8345,8510-8512)$, anaplastic cancer (8020-8035) and other carcinomas. T factor was based on pathological $\mathrm{T}$ stage. For cases where pathological stage was unknown, clinical stage was used. The TNM classification changed significantly during the study period. Classification was based on the fourth edition for study period 1989-1997; fifth edition 1998-2002 and sixth edition after 2002 (Hermanek \& Sobin 1987, Sobin \& Fleming 1997, Wittekind et al. 2002).

Patients $<15$ and $>95$ years were excluded from the survival analysis, as well as cases diagnosed at autopsy. Age at diagnosis was divided into two groups ( $\leq 60$ and $>60$ years). The study period was divided into three categories of 5 years and one of 6 years: 1989-1993, 1994-1998, 1999-2003 and 2004-2009. Incidence rates were calculated per age group, sex, histological type and $\mathrm{T}$ factor.

\section{Statistical analyses}

Annual incidence and mortality rates for the period 1989-2009 were calculated per 100000 person-years, using the mid-year population size as obtained from Statistics Netherlands. Rates were age-standardised to the European standard population (European standardised rates (ESR)). Trends in incidence were evaluated by calculating the estimated annual percentage change (EAPC) and the corresponding 95\% CI. To calculate this, a regression line was fitted to the natural logarithm of the rates, using the calendar year as regressor variable (i.e. $y=$ $a x+b$, where $y=\ln$ (rate) and $x=$ calendar year, then $\left.\mathrm{EAPC}=100 \times\left(e^{\mathrm{a}}-1\right)\right)$. This calculation assumes that the rates increased or decreased at a constant rate over the entire period. Joinpoint analyses were performed to discern significant changes in the trend and, if present, when they occurred (Kim et al. 2000).

Relative survival was used as an estimation of diseasespecific survival. It was derived as the ratio of observed survival of the cancer patients and the expected survival of a comparable age- and sex-matched group of the general population while using the Ederer method (Ederer \& Heise 1959). Cohort-based, relative survival analysis was used to calculate 5-year relative survival.

Survival trends were quantified as the mean period percentage change within the period 1989-2009 estimated by a linear regression model. A positive value of the mean period change implies an upward trend in survival
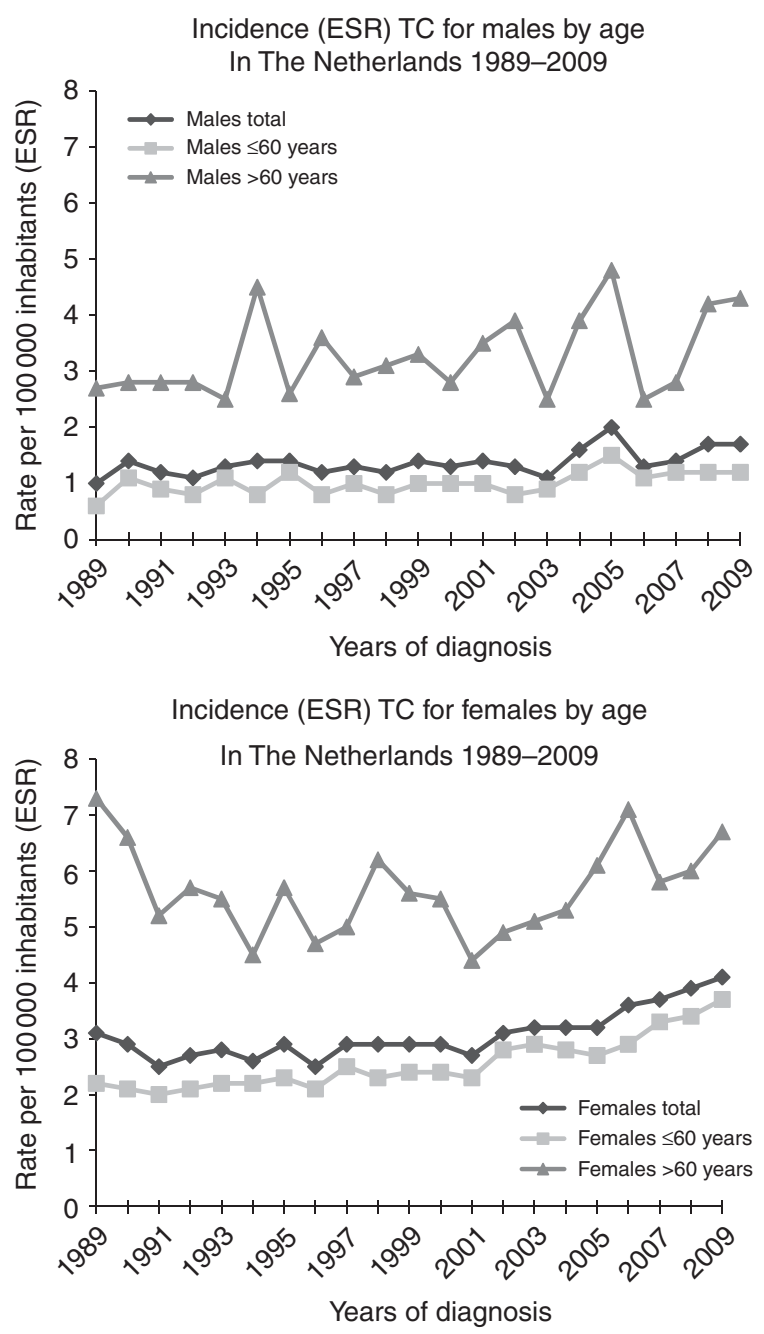

\section{Figure 1}

Three-year moving average of age-standardised incidence rates (ESR) of TC in The Netherlands 1989-2009 according to gender and age group at diagnosis.

Published by Bioscientifica Ltd. 
(i.e. improving) and a negative value implies a negative trend (i.e. deterioration).

Multivariate relative survival analyses, using Poisson regression modelling, were carried out to estimate relative excess risk (RER) of dying adjusted for follow-up interval and age group. SAS Software (SAS System 9.2; SAS Institute, Cary, NC, USA) was used to perform the statistical analyses.

\section{Results}

\section{Trends in incidence}

In The Netherlands 8021 new TC cases were registered between 1989 and 2009. Mean age at diagnosis was $53 \pm 19$ (s.D.) years. The female to male ratio was 2.4:1. The proportion of male patients $<45$ years decreased steadily from $38 \%$ in $1989-1993$ to $32 \%$ in $2004-2009$. In females, $40 \%$ were $<45$ years of age at diagnosis. Furthermore, the proportion of patients 45-59 years increased (Table 1).

The overall incidence rate increased from 2.0 in 1989 to 2.9 per 100000 person-years in 2009 (EAPC $=+1.7 \%$; 95\% CI 1.2-2.3), corresponding to an increase from 315 cases in 1989 to 537 in 2009. For females the incidence rate increased from 3.1 in 1989 to 4.1 per 100000 person-years in 2009 (EAPC $=+1.7 \%$; 95\% CI $1.1-2.4$ ). The EAPC for females changed from $+0.1 \%$ (95\% CI -0.9 to 1.2$)$ before 2001 to $+4.7 \%$ (95\% CI 2.7-6.7) after 2001. For males the incidence rate increased from 1.0 in 1989 to 1.7 per 100000 person-years in 2009 (EAPC $=+1.6 \%$; 95\% CI 1.2-2.3). Incidence rates increased for all age groups, except for females $>60$ years (Fig. 1).

The percentage of papillary TC cases increased for males from $49 \%$ in 1989 to $62 \%$ in 2009 and for females from $53 \%$ in 1989 to $68 \%$ in $2009(P<0.01$; Table 1$)$. The overall incidence rate increased for papillary TC from 1.1 in 1989 to 2.1 per 100000 person-years in 2009 $(\mathrm{EAPC}=+3.5 \%$; 95\% CI 2.4-4.6). For females, the EAPC for papillary TC changed from $0.0 \%$ (95\% CI -2.6 to 2.7 ) before 1996 to $+5.0 \%$ (95\% CI 3.9-6.1) after 1996 (Fig. 2). The incidence of follicular, medullary and anaplastic TC remained relatively stable for both sexes (Fig. 2).

For T1 TC, the incidence rate increased from 0.2 in 1989 to 1.1 per 100000 person-years in 2009 (EAPC $=$ $+7.9 \%$; 95\% CI 5.8-10.0) and for T3 TC the incidence rate increased from 0.2 in 1989 to 0.7 per 100000 person-years in 2009 (EAPC $=+5.8 \%$; 95\% CI 4.1-7.6). The EAPC for T1 TC changed from $+2.1 \%(95 \% \mathrm{CI}-1.3$ to 5.6$)$ before 2002 to $+14.3 \%$ (95\% CI 3.5-26.3) after 2002 and for T3 TC it changed from $+0.2 \%$ (95\% CI -2.6 to 3.1$)$ before 2002 to $+9.5 \%$ (95\% CI 5.9-13.1) after 2002, these joinpoints were only found for females (Fig. 3). The overall incidence rate of T2 TC remained stable from 0.8 in 1989 to 0.7 per 100000 person-years in $2009(\mathrm{EAPC}=-1.1 \%$; 95\% CI -2.2 to 0.02). For females, the EAPC for T2 TC changed from $+1.6 \%$ (95\% CI 0.2-3.0) before 2002 to $+3.9 \%(95 \%$ CI 3.5-26.3) after 2003 (with and decrease of $-49.6 \%$ between 2002 and 2003 due to the change in TNM classification; Fig. 3). This trend was not found for males $(\mathrm{EAPC}=-1.3 \%(95 \% \mathrm{CI}-3.4$ to 0.9$))$. The incidence rate for T4 TC decreased by $-2.3 \%$ (95\% CI -3.3 to 1.4$)$ per year between 1989 and 2009; and changed from $-0.2 \%$ (95\% CI -2.4 to 2.0 ) before 2002 to $-2.4 \%$ (95\% CI -5.6 to 1.0$)$ after 2002.
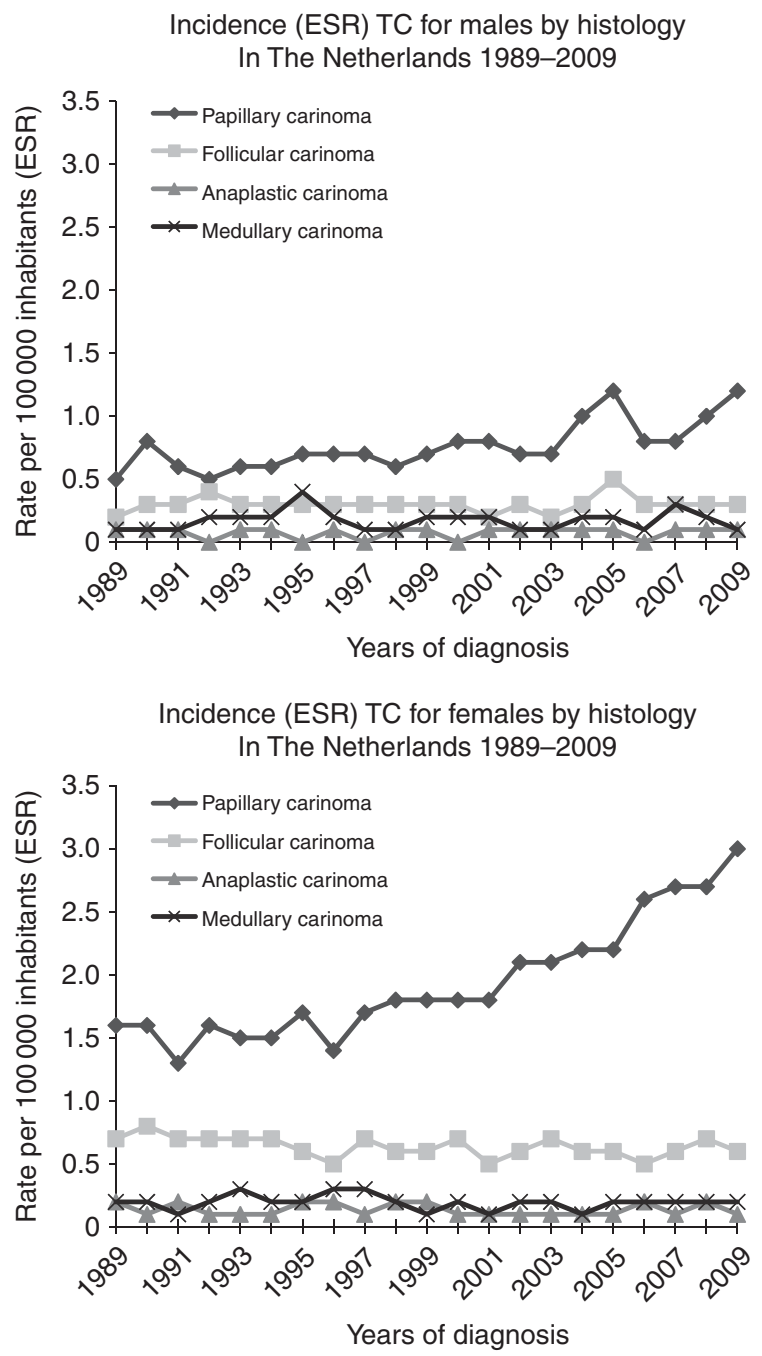

Figure 2

Three-year moving average of age-standardised incidence rates (ESR) of TC in The Netherlands 1989-2009 according to gender and histology.

Published by Bioscientifica Ltd. 

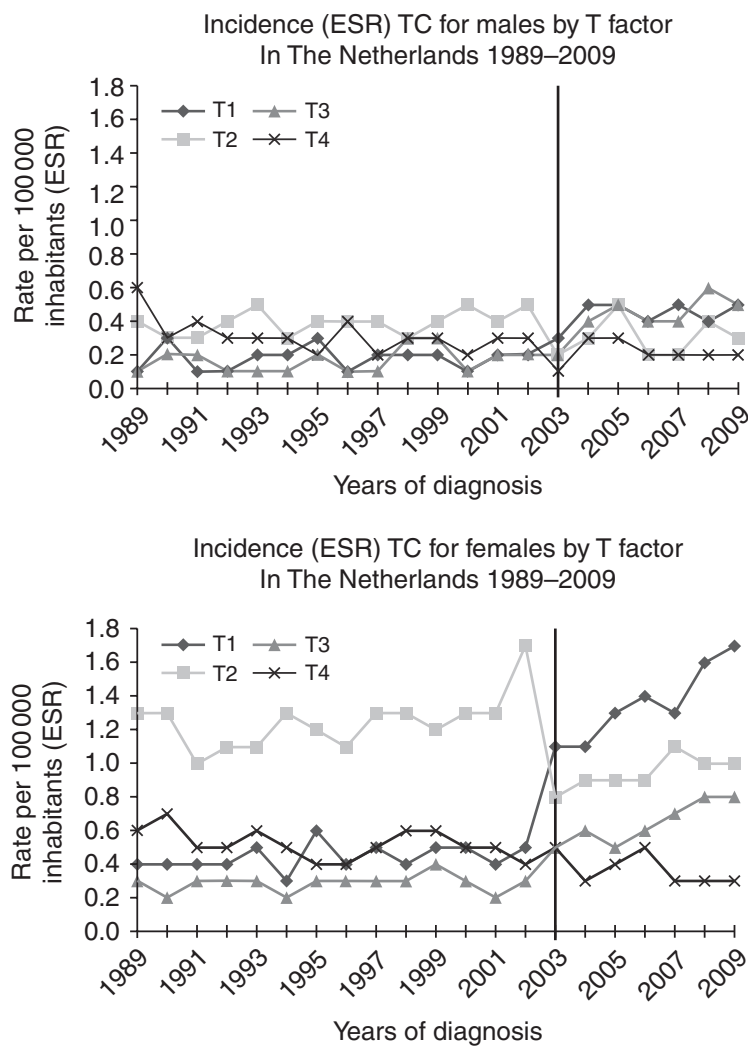

Figure 3

Three-year moving average of age-standardised incidence rates (ESR) of TC in The Netherlands 1989-2009 according to gender and T factor. Vertical line represents the change in TNM classification in 2003. UICC fifth edition: T1 tumour size maximal $1 \mathrm{~cm}$, T2 tumour size $>1$ and $\leq 4 \mathrm{~cm}$, T3 tumour size $>4 \mathrm{~cm}$ limited to the thyroid and T4 any tumour with extrathyroid extension (Sobin \& Fleming 1997). UICC sixth edition: T1 tumour size maximal $2 \mathrm{~cm}$, T2 tumour size $>2$ and $\leq 4 \mathrm{~cm}$, T3 tumour size $>4 \mathrm{~cm}$ limited to thyroid or minimal extrathyroid extension and T4 tumour extends beyond thyroid capsule (Wittekind et al. 2002).

\section{Relative survival}

Overall, 5-year relative survival from TC remained stable, although appeared to increase (not significantly) in males from $74 \%$ in $1989-1993$ to $82 \%$ in 2004-2009 and in females from 78 to $82 \%$ (Table 2). While in 1989-2003, 5 -year relative survival was better for females than in males, this discrepancy disappeared after 2003. Five-year relative survival decreased with increasing age at diagnosis, being $\sim 93 \%$ for $\leq 60$ years and $\sim 44 \%$ for $>60$ years, in the entire study period, and increased nonsignificantly for all age groups over time. Survival decreased with increasing $\mathrm{T}$ factor, with 5-year relative survival of $\sim 96 \%$ for T1 TC in the entire period 1989-2009, while the 5-year relative survival for T2, T3 and T4 TC were respectively $\sim 94, \sim 80$ and $\sim 53 \%$ in the entire study period. A non-significant increase over time was seen in survival of T1, T2 and T3 TC, while survival from T4 TC appeared to decrease over time. Five-year survival rates remained more or less stable for papillary TC ( $\sim 88 \%)$ and follicular TC ( $\sim 77 \%)$ over the entire study period and appeared to decrease slightly for medullary TC from 64 to $61 \%$ in 2004-2009. The 1-year relative survival for anaplastic TC decreased from 18\% in 1989-1993 to $14 \%$ in 2004-2009.

Multivariable relative survival analyses showed an increased risk of death for older patients, patients with a higher $\mathrm{T}$ factor and follicular, anaplastic or medullary tumour type, however no effect for period was found (Table 3).

\section{Trends in mortality}

Mortality decreased with $-1.9 \%$ (95\% CI -2.8 to 0.9$)$ per year between 1989 and 2009 (Fig. 4), more in males $(-2.2 \%)$ than in females $(-1.7 \%)$. In absolute numbers we observed a slight increase from 98 deaths in 1989 to 105 deaths in 2009.

\section{Discussion}

Our study shows that since 1989 the incidence of TC increased significantly in The Netherlands, while mortality from TC decreased. This increase was due to papillary tumours only. The overall 5-year relative survival remained stable and appeared to be somewhat higher for both sexes, all age groups and T1-T3 TC and somewhat lower for T4, medullary and anaplastic TC in the period 2004-2009 compared with earlier periods.

The rising age-standardised incidence of TC in The Netherlands is in concordance with patterns observed in many other European countries and the USA (Ferlay et al. 2010). The increase in our study was mainly due to the increased number of detected small tumours (T1) of papillary histological subtype. This shift to the detection of more T1 papillary tumours can partly be explained by the change in TNM classification in 2002, however the T1 TC incidence rates were already increasing before 2002 (Kuijpens et al. 1998) and incidence rates for T2 TC were also increasing after 2002. The incidence rates started to increase at a younger age in women than in men, possibly related to greater use of health care services by young and middle-aged women compared with men of the same age (Dal Maso et al. 2011). Also, the incidence rate of papillary TC increased more steeply among women (starting around 2001) than men, likely

Published by Bioscientifica Ltd. 
Table 2 Five-year relative survival (S.E.M.) by period of diagnosis, T factor and age.

\begin{tabular}{|c|c|c|c|c|c|c|}
\hline & 1989-1993 & 1994-1998 & 1999-2003 & 2004-2009 & Period change $(95 \% \mathrm{Cl})$ & $P$ value \\
\hline \multicolumn{7}{|l|}{ Sex } \\
\hline Male & $74(2.5)$ & $74(2.4)$ & $74(2.3)$ & $82(2.1)$ & $3.3(-4.1$ to 11.3$)$ & 0.20 \\
\hline Female & 78 (1.4) & $81(1.3)$ & $83(1.2)$ & $82(1.4)$ & $1.4(-1.8$ to 4.8$)$ & 0.20 \\
\hline \multicolumn{7}{|l|}{ Age (years) } \\
\hline$\leq 60$ & $92(0.9)$ & $92(0.9)$ & $94(0.7)$ & $94(0.8)$ & $0.9(-0.6$ to 2.4$)$ & 0.13 \\
\hline$>60$ & $43(2.0)$ & $43(2.0)$ & $41(2.0)$ & $49(2.3)$ & $3.8(-9.2$ to 18.7$)$ & 0.35 \\
\hline \multicolumn{7}{|l|}{$\mathrm{T}$ factor } \\
\hline 1 & $94(2.2)$ & $95(1.8)$ & $95(1.5)$ & $98(1.0)$ & $1.1(-0.7$ to 3.0$)$ & 0.12 \\
\hline 2 & $92(1.5)$ & $95(1.2)$ & $94(1.1)$ & $94(1.7)$ & $0.8(-2.0$ to 3.8$)$ & 0.35 \\
\hline 3 & $76(4.2)$ & $79(3.6)$ & $84(3.0)$ & $81(3.0)$ & $2.6(-3.8$ to 9.5$)$ & 0.23 \\
\hline 4 & $59(3.2)$ & $56(3.2)$ & $56(3.0)$ & 42 (3.9) & $-9.8(-26.4$ to 10.7$)$ & 0.16 \\
\hline \multicolumn{7}{|l|}{ Histology } \\
\hline Papillary carcinoma & $88(1.2)$ & $86(1.2)$ & $88(0.9)$ & $89(1.0)$ & $0.8(-2.5$ to 4.1$)$ & 0.42 \\
\hline Follicular carcinoma & $76(2.1)$ & $77(2.2)$ & $78(2.1)$ & $77(2.8)$ & $0.3(-1.4$ to 2.0$)$ & 0.58 \\
\hline Anaplastic carcinoma & $8(2.9)$ & $4(2.0)$ & $4(1.9)$ & $5(2.3)$ & NA & NA \\
\hline Medullary carcinoma & $64(4.2)$ & $74(3.7)$ & $60(4.7)$ & $61(5.5)$ & $-3.5(-21.1$ to 18.0$)$ & 0.52 \\
\hline
\end{tabular}

NA, not available.

because of the higher number of biopsies performed in this population (Netea-Maier et al. 2008).

The main question debated in the literature is whether or not the observed increase in TC incidence is the result of a real increase in number of cases or of improved detection? A recent study in the USA showed a significant decrease in tumour size over time and concluded that the apparent increase in TC incidence was largely due to more detection of non-symptomatic tumours (Kent et al. 2007). It has been shown that TC can exist as subclinical entity since at least one-third of the adults have subclinical TC at autopsies (Harach et al. 1985). Improved detection by the increased use of and improved (resolution of) diagnostic tools and medical surveillance might be responsible for the detection of more subclinical disease and could also have resulted in a shift in detection from more advanced tumours to early-stage tumours. Nevertheless, incidence rates also increased for $\mathrm{T} 3 \mathrm{TC}$, and this increase was larger than the decrease in incidence rates of T4 TC. This increasing trend might be less related to the improved detection and increased surveillance. True increases in incidences of TC have been associated with different risk factors like exposure to ionising radiation (fallout, diagnostic tests like computed tomography scans and treatments like radiotherapy), low iodine intake (Liu et al. 2009, Ceresini et al. 2012) and overweight (Kitahara et al. 2011). However, none of these factors have been proven as risk factors in The Netherlands. Therefore, more research into the events involved in the initiation and progression of TC is needed.

http://erc.endocrinology-journals.org DOI: 10.1530/ERC-12-0336

(c) 2013 Society for Endocrinology Printed in Great Britain
Five-year relative survival rates for differentiated TC (papillary or follicular) were high and within the range of rates described for the USA (Yu et al. 2010) and Europe (Verdecchia et al. 2007). The small differences suggest corresponding differences in the availability of diagnostic and treatment options, and in the effectiveness of health care systems. The non-significant decrease in 5-year relative survival rates for $\mathrm{T} 4 \mathrm{TC}$ could be explained by the decrease in the incidence of the slowly growing T4 TC,

Table 3 Relative excess risk (RER) of dying for TC patients in The Netherlands.

\begin{tabular}{|c|c|c|}
\hline Variable & RER & $95 \% \mathrm{Cl}$ \\
\hline \multicolumn{3}{|l|}{ Period of diagnosis } \\
\hline 1989-1993 & 1 & \\
\hline 1994-1998 & 1.1 & $0.9-1.4$ \\
\hline 1999-2003 & 1.1 & $0.9-1.4$ \\
\hline $2004-2008$ & 1.0 & $0.8-1.2$ \\
\hline \multicolumn{3}{|l|}{ Sex } \\
\hline Male & 1 & \\
\hline Female & 0.9 & $0.8-1.1$ \\
\hline \multicolumn{3}{|l|}{ Age group (years) } \\
\hline$\leq 60$ & 1 & \\
\hline$>60$ & $4.8^{*}$ & $3.9-6.0$ \\
\hline \multicolumn{3}{|l|}{ T factor } \\
\hline 1 & 1 & \\
\hline 2 & 1.5 & $0.9-2.4$ \\
\hline 3 & $2.9 *$ & $1.8-4.6$ \\
\hline 4 & $5.8^{*}$ & $3.7-9.2$ \\
\hline \multicolumn{3}{|l|}{ Histology } \\
\hline Papillary carcinoma & 1 & \\
\hline Follicular carcinoma & $1.4^{*}$ & $1.1-1.8$ \\
\hline Anaplastic carcinoma & $19.5^{*}$ & $15.4-24.8$ \\
\hline Medullary carcinoma & $4.2^{*}$ & $3.2-5.6$ \\
\hline
\end{tabular}

$\star P<0.05$, adjusted for follow-up interval.

Published by Bioscientifica Ltd. 


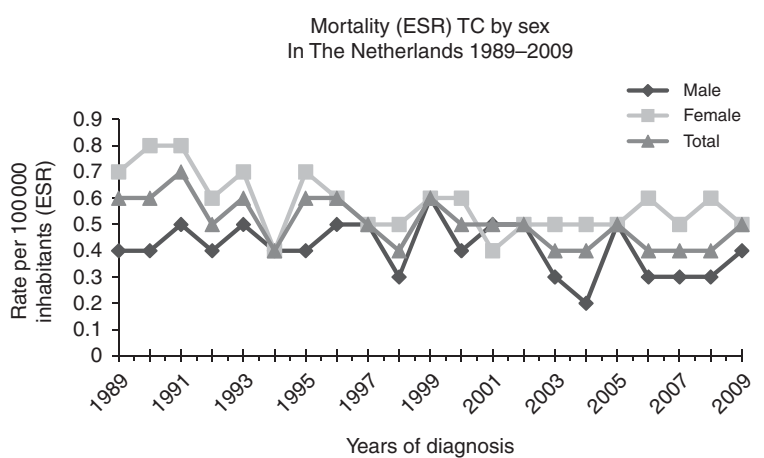

Figure 4

Three-year moving average of age-standardised mortality rates of TC in The Netherlands 1989-2009 according to gender and age group at diagnosis.

indicating that those tumours are earlier detected as $\mathrm{T} 3$ TC. Furthermore, since 2002 any tumour with minimal extrathyroidal extension is registered as T3 instead of T4 TC and all anaplastic tumours are registered as T4 TC, leaving the truly advanced cancers with a worse prognosis as $\mathrm{T} 4 \mathrm{TC}$, which could explain the decrease in survival rates for these tumours.

Five-year relative survival rates for anaplastic (5.6-11.4\% depending on race) and medullary cancer (73.5-88.7\% depending on race) were higher is the USA compared with The Netherlands (Yu et al. 2010). The low incidence rates of both tumours have limited the development of clinical expertise and conduction of randomised clinical trials (Kloos et al. 2009). The American Thyroid Association recently came up with evidencebased management guidelines for medullary (Kloos et al. 2009) and anaplastic TC (Smallridge et al. 2012). Dissemination of standardised guidelines to Europe is important to ensure optimal treatment for these patients. Recently, a study showed improved disease-specific survival for a subpopulation of anaplastic TC patients who were treated by aggressive multimodal regimes based on a prognostic index (Orita et al. 2011). Application of this prognostic index in The Netherlands could possibly lead to some improvements in survival rates for this most lethal tumour.

The increased incidence of TC was not accompanied by a concurrent increase in TC mortality which even decreased for both men and women, equal to other studies in Europe (Pacini et al. 2010) and the USA (Sipos \& Mazzaferri 2010). Many of the detected tumours were indeed small treatable cancers. The detection of these small tumours could have preceded development of more advanced cancers (T4 TC) or tumours with more unfavourable prognosis such as medullary and anaplastic cancers whose incidence remained stable and whose prognosis slightly decreased.

Since a large part of the increased incidence in our study can be ascribed to the detection of small (subclinical) tumours, overdiagnosis of clinically irrelevant cancer might be occurring (Welch \& Black 2010). Indeed, most patients with cytological indeterminate nodules are referred for diagnostic thyroid surgery, but the majority (66\%) prove to have benign disease (Wang et al. 2011) and for these patients surgery is unnecessary (Alexander et al. 2012).

It has been hypothesised that increased detection of low-risk tumours can lead to an overestimation of treatment efficacy and a subsequent rise in use of treatment (Haymart et al. 2011). Up to now, there is a lack of randomised controlled trials to support management decisions for small and low-risk tumours. For patients with early-stage differentiated TC whose primary tumour is $>1 \mathrm{~cm}$ the guidelines recommend total thyroidectomy and radioactive iodine treatment to be selectively considered (Pacini et al. 2010). Nevertheless, treatment with radioactive iodine is of uncertain benefit for patients with low-risk disease (Schvartz et al. 2012). In addition, the majority of patients with early-stage differentiated TC will have a favourable outcome and many of these tumours would remain asymptomatic during lifetime (Pacini 2012) However, a small proportion of these patients will experience recurrent disease with increased morbidity (Momesso et al. 2012). There is a need to improve the pre-operative evaluation of low-risk thyroid nodules in order to prevent potential overtreatment and in addition to this a more conservative surgical approach without radioiodine therapy should be considered for low-risk patients (Momesso et al. 2012). A complete understanding of the various prognostic factors is important to advise the patient accordingly on the best treatment and long-term surveillance (Sipos \& Mazzaferri 2010). This is important since we recently showed that problems and symptoms of TC and its treatment can be detected up to 20 years after diagnosis (Husson et al. 2013). These late symptoms were mostly related to thyroid dysregulation (neuromuscular, concentration, sympathetic, psychological and sensory problems) and not so much to specific morbidities as a consequence of surgery (voice problems, throat/mouth problems and problems with scar). Longterm health problems are becoming more important since the prevalence of TC survivors who received more or less aggressive/invasive treatment is increasing and will probably lead to an increased burden on health care in the coming years.

Published by Bioscientifica Ltd. 
By combining the three epidemiologic determinants of TC burden (i.e. incidence, mortality and survival) with essential prognostic determinants we achieved a more comprehensive assessment of the progress against TC, however also quality of life assessments should be added (Husson et al. 2011). Some limitations of this study require consideration. Despite the rather clinical nature of the NCR, lack of details regarding applied primary treatments in our population-based registry limited the potential to explore and elucidate specific reasons for the observed changes in survival. Furthermore, since the TNM staging system changed significantly in 2002, and the NCR did not provide us with information on the exact tumour size, it was impossible to use a uniform staging system for our analyses, which hampered the interpretation of our results.

In conclusion, TC detection and incidence has been rising in The Netherlands, while mortality rates are decreasing and survival rates remained stable and appeared to be somewhat higher except for advanced tumours of which the frequency decreased markedly.

\section{Declaration of interest}

The authors declare that there is no conflict of interest that could be perceived as prejudicing the impartiality of the research reported.

\section{Funding}

This study was performed as part of the project 'Progress against cancer in The Netherlands since the 1970s' (Dutch Cancer Society Grant EMCR 2006-3489). The study sponsors had no role in the study design, in the collection, analysis and interpretation of data; in the writing of the manuscript; and in the decision to submit the manuscript for publication. We are grateful for the dedicated data collection by the various registration teams of the Netherlands Cancer Registry.

\section{Author contribution statement}

O Husson, H R Haak, LV van de Poll-Franse and J W W Coebergh contributed to the concept and design of the study. $\mathrm{H}$ Karim-Kos contributed to the acquisition of the data. $\mathrm{O}$ Husson and $\mathrm{L} N$ van Steenbergen analysed the data. O Husson drafted the manuscript. All authors (O Husson, H R Haak, L N van Steenbergen, W-A Nieuwlaat, B A C van Dijk, G A P Nieuwenhuijzen, H Karim-Kos, J L Kuijpens, L V van de Poll-Franse and J W W Coebergh) provided input to the manuscript and have approved the final manuscript.

\section{References}

Alexander EK, Kennedy GC, Baloch ZW, Cibas ES, Chudova D, Diggans J, Friedman L, Kloos RT, Livolsi VA, Mandel SJ et al. 2012 Preoperative diagnosis of benign thyroid nodules with indeterminate cytology. New England Journal of Medicine 367 705-715. (doi:10.1056/ NEJMoa1203208)
Cardis E, Krewski D, Boniol M, Drozdovitch V, Darby SC, Gilbert ES, Akiba S, Benichou J, Ferlay J, Gandini S et al. 2006 Estimates of the cancer burden in Europe from radioactive fallout from the Chernobyl accident. International Journal of Cancer 119 1224-1235. (doi:10.1002/ ijc.22037)

Ceresini G, Corcione L, Michiara M, Sgargi P, Teresi G, Gilli A, Usberti E, Silini E \& Ceda GP 2012 Thyroid cancer incidence by histological type and related variants in a mildly iodine-deficient area of Northern Italy, 1998 to 2009. Cancer 118 5473-5480.

Dal Maso L, Lise M, Zambon P, Falcini F, Crocetti E, Serraino D, Cirilli C, Zanetti R, Vercelli M, Ferretti S et al. 2011 Incidence of thyroid cancer in Italy, 1991-2005: time trends and age-period-cohort effects. Annals of Oncology 22 957-963. (doi:10.1093/annonc/mdq467)

Davies L \& Welch HG 2006 Increasing incidence of thyroid cancer in the United States, 1973-2002. Journal of the American Medical Association 295 2164-2167. (doi:10.1001/jama.295.18.2164)

Ederer F \& Heise H 1959 Instructions to IBM 650 programmers in processing survival computations. Bethesda, MD, USA: National Cancer Institute.

Ferlay J, Shin HR, Bray F, Forman D, Mathers C \& Parkin DM 2010 Estimates of worldwide burden of cancer in 2008: GLOBOCAN 2008. International Journal of Cancer 127 2893-2917. (doi:10.1002/ijc.25516)

Fritz A, Percy C, Jack A, et al. 2000 In International Classification of Diseases for Oncology. Geneva, Switzerland: World Health Organisation.

Harach HR, Franssila KO \& Wasenius VM 1985 Occult papillary carcinoma of the thyroid. A "normal" finding in Finland. A systematic autopsy study. Cancer 56 531-538. (doi:10.1002/1097-0142(19850801)56:3< 531::AID-CNCR2820560321>3.0.CO;2-3)

Haymart MR, Banerjee M, Stewart AK, Koenig RJ, Birkmeyer JD \& Griggs JJ 2011 Use of radioactive iodine for thyroid cancer. Journal of the American Medical Association 306 721-728. (doi:10.1001/jama.2011.1139)

Hermanek P \& Sobin LH 1987 In TNM Classification of Malignant Tumours. Berlin, Germany: Springer-Verlag.

Husson O, Haak HR, Oranje WA, Mols F, Reemst PH \& van de Poll-Franse LV 2011 Health-related quality of life among thyroid cancer survivors: a systematic review. Clinical Endocrinology 75 544-554. (doi:10.1111/ j.1365-2265.2011.04114.x)

Husson O, Haak HR, Buffart LM, Nieuwlaat W, Oranje WA, Mols F, Kuijpens JL, Coebergh JW \& Van de Poll-Franse LV 2013 Health-related quality of life and disease specific symptoms among (long-term) thyroid cancer survivors: a study from the population-based PROFILES registry. Acta Oncologica 52 249-258. (doi:10.3109/0284186X.2012.741326)

Kent WD, Hall SF, Isotalo PA, Houlden RL, George RL \& Groome PA 2007 Increased incidence of differentiated thyroid carcinoma and detection of subclinical disease. CMAJ: Canadian Medical Association Journal 177 1357-1361. (doi:10.1503/cmaj.061730)

Kim HJ, Fay MP, Feuer EJ \& Midthune DN 2000 Permutation tests for joinpoint regression with applications to cancer rates. Statistics in Medicine 19 335-351. (doi:10.1002/(SICI)1097-0258(20000215) 19:3<335::AID-SIM336>3.0.CO;2-Z)

Kitahara CM, Platz EA, Freeman LE, Hsing AW, Linet MS, Park Y, Schairer C, Schatzkin A, Shikany JM \& Berrington de Gonzalez A 2011 Obesity and thyroid cancer risk among U.S. men and women: a pooled analysis of five prospective studies. Cancer Epidemiology, Biomarkers \& Prevention 20 464-472. (doi:10.1158/1055-9965.EPI-10-1220)

Kloos RT, Eng C, Evans DB, Francis GL, Gagel RF, Gharib H, Moley JF, Pacini F, Ringel MD, Schlumberger M et al. 2009 Medullary thyroid cancer: management guidelines of the American Thyroid Association. Thyroid 19 565-612. (doi:10.1089/thy.2008.0403)

Kuijpens JL, Hansen B, Hamming JF, Ribot JG, Haak HR \& Coebergh JW 1998 Trends in treatment and long-term survival of thyroid cancer in Southeastern Netherlands, 1960-1992. European Journal of Cancer 34 1235-1241. (doi:10.1016/S0959-8049(98)00133-6)

Liu XH, Chen GG, Vlantis AC \& van Hasselt CA 2009 Iodine mediated mechanisms and thyroid carcinoma. Critical Reviews in Clinical Laboratory Sciences 46 302-318. (doi:10.3109/10408360903306384) 
Momesso DP, Vaisman F, Cordeiro de Noronha Pessoa CH, Corbo R \& Vaisman M 2012 Small differentiated thyroid cancer: time to reconsider clinical management and treatment. Surgical Oncology [in press].

Netea-Maier RT, Aben KK, Casparie MK, den Heijer M, Grefte JM, Slootweg P $\&$ Hermus A 2008 Trends in incidence and mortality of thyroid carcinoma in The Netherlands between 1989 and 2003: correlation with thyroid fine-needle aspiration cytology and thyroid surgery. International Journal of Cancer 123 1681-1684. (doi:10.1002/ijc.23678)

Orita Y, Sugitani I, Amemiya T \& Fujimoto Y 2011 Prospective application of our novel prognostic index in the treatment of anaplastic thyroid carcinoma. Surgery 150 1212-1219. (doi:10.1016/j.surg.2011.09.005)

Pacini F 2012 Thyroid microcarcinoma. Best Practice \& Research. Clinical Endocrinology \& Metabolism 26 381-389. (doi:10.1016/j.beem. 2011.10.006)

Pacini F, Castagna MG, Brilli L \& Pentheroudakis G 2010 Thyroid cancer: ESMO Clinical Practice Guidelines for diagnosis, treatment and followup. Annals of Oncology 21 (Suppl 5) v214-v219. (doi:10.1093/annonc/ mdq190)

Schneider AB \& Sarne DH 2005 Long-term risks for thyroid cancer and other neoplasms after exposure to radiation. Nature Clinical Practice. Endocrinology \& Metabolism 1 82-91. (doi:10.1038/ncpendmet0022)

Schvartz C, Bonnetain F, Dabakuyo S, Gauthier M, Cueff A, Fieffe S, Pochart JM, Cochet I, Crevisy E, Dalac A et al. 2012 Impact on overall survival of radioactive iodine in low-risk differentiated thyroid cancer patients. Journal of Clinical Endocrinology and Metabolism 97 1526-1535. (doi:10.1210/jc.2011-2512)

Sipos JA \& Mazzaferri EL 2010 Thyroid cancer epidemiology and prognostic variables. Clinical Oncology 22 395-404. (doi:10.1016/j.clon.2010. 05.004)
Smallridge RC, Ain KB, Asa SL, Bible KC, Brierley JD, Burman KD, Kebebew E, Lee NY, Nikiforov YE, Rosenthal MS et al. 2012 American Thyroid Association guidelines for management of patients with anaplastic thyroid cancer. Thyroid 22 1104-1139. (doi:10.1089/thy.2012.0302)

Sobin LH \& Fleming ID 1997 TNM Classification of malignant tumors, fifth edition (1997). Union Internationale Contre le Cancer and the American Joint Committee on Cancer. Cancer 80 1803-1804. (doi:10.1002/(SICI)1097-0142(19971101)80:9 < 1803::AID-CNCR16> 3.0.CO;2-9)

Verdecchia A, Francisci S, Brenner H, Gatta G, Micheli A, Mangone L \& Kunkler I 2007 Recent cancer survival in Europe: a 2000-02 period analysis of EUROCARE-4 data. Lancet Oncology 8 784-796. (doi:10.1016/S1470-2045(07)70246-2)

Wang CC, Friedman L, Kennedy GC, Wang H, Kebebew E, Steward DL, Zeiger MA, Westra WH, Wang Y, Khanafshar E et al. 2011 A large multicenter correlation study of thyroid nodule cytopathology and histopathology. Thyroid 21 243-251. (doi:10.1089/thy.2010.0243)

Welch HG \& Black WC 2010 Overdiagnosis in cancer. Journal of the National Cancer Institute 102 605-613. (doi:10.1093/jnci/djq099)

Wittekind C, Compton CC, Greene FL \& Sobin LH 2002 TNM residual tumor classification revisited. Cancer 94 2511-2516. (doi:10.1002/ cncr.10492)

Yu GP, Li JC, Branovan D, McCormick S \& Schantz SP 2010 Thyroid cancer incidence and survival in the national cancer institute surveillance, epidemiology, and end results race/ethnicity groups. Thyroid $\mathbf{2 0}$ 465-473. (doi:10.1089/thy.2008.0281)

van der Zwan JM, Mallone S, van Dijk B, Bielska-Lasota M, Otter R, Foschi R, Baudin E \& Links TP 2012 Carcinoma of endocrine organs: results of the RARECARE project. European Journal of Cancer $\mathbf{4 8}$ 1923-1931. (doi:10.1016/j.ejca.2012.01.029)

Received in final form 13 February 2013

Accepted 25 February 2013

Made available online as an Accepted Preprint

26 February 2013
(C) 2013 Society for Endocrinology Printed in Great Britain 